\title{
The changes of nociception and the signal molecules expression in the dorsal root ganglia and the spinal cord after cold water swimming stress in mice
}

\author{
Jing-Hui Feng ${ }^{1}$, Su-Min Sim', Jung-Seok Park'2, Jae-Seung Hong ${ }^{2}$, and Hong-Won Suh ${ }^{1, *}$ \\ ${ }^{1}$ Department of Pharmacology and Institute of Natural Medicine, College of Medicine, Hallym University, ${ }^{2}$ Department of Physical Education, Hallym University, \\ Chuncheon 24252, Korea
}

\section{ARTICLE INFO}

Received October 29, 2020

Revised January 25, 2021

Accepted February 17, 2021

\section{*Correspondence}

Hong-Won Suh

E-mail: hwsuh@hallym.ac.kr.

Key Words

Dorsal root ganglia

Nociception

Proteins

Spinal cord

\begin{abstract}
Several studies have previously reported that exposure to stress provokes behavioral changes, including antinociception, in rodents. In the present study, we studied the effect of acute cold-water $\left(4^{\circ} \mathrm{C}\right)$ swimming stress (CWSS) on nociception and the possible changes in several signal molecules in male ICR mice. Here, we show that 3 min of CWSS was sufficient to produce antinociception in tailflick, hot-plate, von-Frey, writhing, and formalin-induced pain models. Significantly, CWSS strongly reduced nociceptive behavior in the first phase, but not in the second phase, of the formalin-induced pain model. We further examined some signal molecules' expressions in the dorsal root ganglia (DRG) and spinal cord to delineate the possible molecular mechanism involved in the antinociceptive effect under CWSS. CWSS reduced p-ERK, p-AMPK $\alpha 1$, p-AMPK $\alpha 2$, p-Tyk2, and p-STAT3 expression both in the spinal cord and DRG. However, the phosphorylation of mTOR was activated after CWSS in the spinal cord and DRG. Moreover, p-JNK and p-CREB activation were significantly increased by CWSS in the spinal cord, whereas CWSS alleviated JNK and CREB phosphorylation levels in DRG. Our results suggest that the antinociception induced by CWSS may be mediated by several molecules, such as ERK, JNK, CREB, AMPK $\alpha 1$, AMPK $\alpha 2$, mTOR, Tyk2, and STAT3 located in the spinal cord and DRG.
\end{abstract}

\section{INTRODUCTION}

Many acute stressors reduce nociceptive responses, a phenomenon called stress-induced antinociception (SIA). Especially in the past 30 years, a series of studies have reported that cold water swimming stress (CWSS) induces antinociception. Several lines of evidence have demonstrated that cold water swimming induces antinociception in selected animal models of pain, including the hot-plate, tail-flick, and formalin tests [1-4]. However, the exact mechanisms involved in SIA have not been well investigated.

Pain transmits from somatosensory neurons present in dorsal root ganglia (DRG) that project to the spinal cord [5-8]. Environmental stimuli are converted into voltage changes in somato- sensory neurons by ionic transducer channels that respond to specific thermal, mechanical, and chemical stimuli and activate sodium channels that generate and propagate action potentials to the DRG. The spinal cord receives the stimuli, which are transferred by the peripheral nervous system. Then the brain originates the descending modulation to adapt to the stimuli [9]. Thus, the spinal cord and DRG are the critical regions involved in pain transmission and stress response.

Although the exact mechanisms involved in CWSS-induced antinociception have not been well revealed, several authors have reported several molecules that are related to the pain in several models. For example, the signal transduction pathway of mitogen-activated protein kinase (MAPK) in the spinal cord

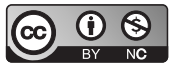

This is an Open Access article distributed under the terms of the Creative Commons Attribution Non-Commercial License, which permits unrestricted non-commercial use, distribution, and reproduction in any medium, provided the original work is properly cited. Copyright @ Korean J Physiol Pharmacol, pISSN 1226-4512, elSSN 2093-3827
Author contributions: J.H.F. methodology, data curation, writing-original draft, and revise. S.M.S. and J.S.P. methodology, data curation. J.S.H. and H.W.S. conceptualization, methodology, data curation, supervision. 
and DRG, including extracellular signal-regulated kinase (ERK), P38, and c-Jun N-terminal kinase (JNK), is closely related to inflammatory and neuropathic pain [10-14]. Besides, the phosphorylated adenosine monophosphate protein kinase (AMPK) is downregulated in the spinal cord and DRG under neuropathic pain [15-17]. Moreover, the suppression of mammalian target of rapamycin (mTOR) could attenuate pain-related hypersensitivity in DRG $[18,19]$. Furthermore, the Janus kinase (JAK)-signal transducer and activator of transcription (STAT) pathway in the spinal cord has been recognized as a pivotal component in the cancer, inflammatory, and neuropathic pain models [20-22].

The exact roles of some nociception-related signaling molecules in regulating CWSS-induced antinociception has not been fully elucidated yet. Thus, in the present study, we first investigated the effects of CWSS on nociceptive behavior using various pain models. Furthermore, we examined the possible roles of signal molecules, such as ERK, JNK, cAMP response element binding (CREB), AMPK, mTOR, Tyrosine Kinase 2 (Tyk2), and STAT3 proteins in the spinal cord and DRG after CWSS in mice.

\section{METHODS}

\section{Experimental animals}

Male ICR mice weighing 20-25 g were purchased from MJ Co., Seoul, Korea, and divided into several groups. Each group consisted of 5 mice. Animals were kept in a room maintained at $22^{\circ} \mathrm{C}$ $\pm 0.5^{\circ} \mathrm{C}$ with a $12: 12 \mathrm{~h}$ light-dark cycle and unlimited access to food and water. The animals were allowed to adapt to the laboratory at least two hours before testing and were only used once. All experiments were carried out between 10:00 and 17:00. The study protocol was approved by the Hallym University Animal Care and Use Committee (Registration Number: Hallym R1 2017-57) following the "Guide for Care and Use of Laboratory Animals" published by the National Institutes of Health and the ethical guidelines of the International Association for the Study of Pain.

\section{Cold water swimming stress}

The mice were forced to swim in cold $\left(4^{\circ} \mathrm{C}\right)$ water for 3 min. They swam in a container $15 \mathrm{~cm}$ in diameter and $20 \mathrm{~cm}$ tall with water filled to a depth of $11 \mathrm{~cm}$. After the swimming, the mice were gently dried by patting their bodies with paper towels.

\section{Nociceptive behavior tests}

\section{Tail-flick test}

We measured mice's response time using the tail-flick test before performing CWSS and then set it as the control group. Antinociception was determined at 0, 10, 20, and $30 \mathrm{~min}$ after CWSS by the tail-flick test [23]. Mice were gently held with one hand with the tail positioned in the apparatus (Model TF6; EMDIE Instrument Co., Maidens, VA, USA). The tail-flick response was elicited by applying radiant heat to the dorsal surface of the tail. The intensity of radiant heat was adjusted so that the animal flicked its tail within 3 to $5 \mathrm{sec}$. In the absence of a withdrawal reflex, set the stimulus cutoff to $15 \mathrm{sec}$ to avoid possible tissue damage.

\section{Hot-plate test}

Mice were performed to the hot plate test before being forced to CWSS, as the control group. Antinociception was determined at $0,10,20$, and $30 \mathrm{~min}$ after CWSS by the hot-plate paw-licking test [24]. Mice were individually placed on the $55^{\circ} \mathrm{C}$ hot-plate apparatus (Model 39 Hot Plate; Itic Life Science, Woodland Hills, CA, USA). Then, the reaction time starting from the mouse's placement on the hotplate to licking the front paw was measured. Basal latency for the hot-plate test was approximately $7 \mathrm{sec}$.

\section{von-Frey test}

Mice were individually placed in a clear glass cell with a metal mesh floor allowed to adapt to the testing environment for 30 min. Before performing CWSS, we analyzed the paw withdrawal threshold of mice using the von-Frey test, then set it as the control group. The mechanical response was assessed at $0,10,20$, and 30 min after CWSS by von-Frey test [25]. Then von-Frey filaments (North Coast Medical, Inc., Gilroy, CA, USA) were applied to the plantar surface using an up and down paradigm. The number of animals used in the experiment was 5 in each group.

\section{Intraplanar formalin tests}

ICR mice were separated into 2 groups, the control group (as the normal mice before injection) and the CWSS group. As described by Hunskaar and Hole [26,27], $10 \mu \mathrm{l}$ of $5 \%$ formalin was injected subcutaneously (s.c.) into the left hind paw. Then the mice were placed immediately in an acrylic observation chamber. Quantification of nociception was based on the animal behaviors (licking, shaking, or biting the injected paw) during 40 min using a stopwatch manually. The first phase (acute pain) was considered 0-5 min, following an interphase (6-20 $\mathrm{min})$, the second phase (inflammatory) continued from 20 to $40 \mathrm{~min}$ after injection.

\section{Acetic acid-induced writhing test}

We separated ICR mice into 2 groups, the control group (as the normal mice before injection) and the CWSS group. As we described previously [28], the mice were injected i.p. with $1 \%$ acetic acid and then were placed in an acrylic observation chamber immediately. The number of writhing was counted over the following $30 \mathrm{~min}$ after CWSS. Writhe was defined as an abdominal contraction of the forelimbs and elongation of the body.

\section{Protein extraction and Western blot}

ICR mice (24 in total) were divided into 4 groups comprising 6 animals each. Mice were decapitated at 0,15 , or $30 \mathrm{~min}$ after CWSS, and then the lumbar section of the DRG and spinal cord was dissected immediately. We also collected the DRG and spinal 
cord of the normal group. Tissue samples were washed twice with cold Tris-buffered saline (20 mM Trizma base and $137 \mathrm{mM}$ $\mathrm{NaCl}, \mathrm{pH}$ 7.5), immediately frozen, and stored in the ultra-lower temperature refrigerator $\left(-80^{\circ} \mathrm{C}\right)$ until assay. The dissected spinal tissues were lysed with sodium dodecyl sulfate lysis buffer (62.5 $\mathrm{mM}$ Trizma base, $2 \% \mathrm{w} / \mathrm{v}$ sodium dodecyl sulfate, $10 \%$ glycerol) containing $0.1 \mathrm{mM} \mathrm{Na}_{3} \mathrm{VO}_{4}, 3 \mathrm{mg} / \mathrm{ml}$ aprotinin, and $20 \mathrm{mM} \mathrm{NaF}$. The sample was then centrifuged at $13,000 \mathrm{rpm}$ for $15 \mathrm{~min}$ at $4^{\circ} \mathrm{C}$, and the supernatant was retained. Protein concentrations were evaluated with the Bradford method (Bio-Rad Laboratories, Hercules, CA, USA) using bovine serum albumin as the standard. The samples were boiled after adding bromophenol blue $(0.1 \%$ $\mathrm{w} / \mathrm{v})$. Equal amounts of protein were resolved by $6 \%-10 \%$ SDSpolyacrylamide gel electrophoresis system and transferred to a polyvinylidene difluoride membrane (Millipore, Bedford, MA, USA). After blocking ( $2 \mathrm{~h}$ at room temperature) with $5 \%$ skim milk in Tris-buffered saline containing 20\% Tween-20 (TBST; $10 \mathrm{mM}$ Trizma base, $\mathrm{pH} 8.0,150 \mathrm{mM} \mathrm{NaCl}$, and $0.2 \%$ Tween 20 ), the membranes were immunoblotted with antibodies pERK (Cell Signaling Technology, 1:1,000), p-JNK (Cell Signaling Technology, 1:1,000), p-CREB (Abcam, 1:1,000), p-AMPKa1 (Abcam, 1:1,000), p-AMPKa2 (Abcam, 1:1,000), p-mTOR (Abcam, 1:1,000), p-STAT3 (Cell Signaling Technology, 1:1,000), p-Tyk2 (Cell Signaling Technology, 1:1,000), and $\beta$-actin (Cell Signaling Technology, 1:1,000) in a blocking buffer for overnight at $4^{\circ} \mathrm{C}$. The membranes were then washed 4 times with TBST for $20 \mathrm{~min}$ and incubated with the anti-rabbit IgG-horseradish peroxidaseconjugated secondary antibody (Enzo Life Sciences, 1:4,000) in blocking buffer at room temperature for $1 \mathrm{~h}$. After washing the membranes with TBST for $20 \mathrm{~min}$ (4 times), the antibody-antigen complexes were detected using the ECL system and exposed to Luminescent Image Analyzer (LAS-4000; Fuji Film Co., Tokyo, Japan) for the detection of light emission. All antibodies' band densities were evaluated from the respective band densitometry. The Multi-Gauge Version 3.1 (Fuji Film Co.) was used to analyze the intensity of expression. These values were expressed as the percentage of the control tested protein $/ \beta$-actin for each sample.

\section{Statistical analysis}

Statistical analysis was performed with the aid of GraphPad Prism (version 8.0.2; GraphPad Software, San Diego, CA, USA). All values were expressed as the mean \pm standard error of the mean (SEM). The statistical significance of differences among multiple variables were assessed with one-way ANOVA, followed when necessary by Bonferroni test. Data were compared between groups using unpaired $t$ test. Differences were considered significant, where $p<0.05$.

\section{RESULTS}

\section{Effect of CWSS on nociceptive behavior in various pain models}

Mice were forced into CWSS for $3 \mathrm{~min}$. Then the nociceptive behavior was measured. In the tail-flick and hot-plate tests, the response time were increased after 3 min CWSS, as shown in Fig. $1 \mathrm{~A}$ and $\mathrm{B}$. In the von-Frey test, the withdrawal threshold was increased after 3 min CWSS (Fig. 1C). However, these antinociceptive effect induced by CWSS were recovered to a normal level after $10 \mathrm{~min}$ of CWSS. In the formalin-induced pain model, the nociceptive behavior during the first phase was reduced after CWSS (Fig. 1D). In contrast, CWSS altered nociceptive behavior mildly during the second phase, which was not significant (Fig. 1D). As shown in Fig. 1E, in the writhing test, the number of writhing responses was suppressed entirely by CWSS during $0-10$ min. Then antinociceptive effect induced by CWSS was mildly reduced but not reversal to a normal level even after $30 \mathrm{~min}$.

\section{Effect of CWSS on ERK, JNK, CREB proteins phosphorylation in the spinal cord and DRG}

The expression of ERK, JNK, or CREB protein phosphorylation was evaluated by Western blot. The lumbar spinal cord and DRG were dissected at 0,15 , and 30 min after cold water swimming stress. CWSS caused up-regulation of p-JNK and p-CREB expression, whereas down-regulation of p-ERK by CWSS in the spinal cord was observed (Fig. 2A-C). CWSS suppressed the expression level of $\mathrm{p}$-ERK, which remained lower than that of the normal level $30 \mathrm{~min}$ after CWSS (Fig. 2A). The JNK phosphorylation level was increased immediately, remained after $15 \mathrm{~min}$, and then reversed to normal level after $30 \mathrm{~min}$ of CWSS (Fig. $2 B$ ). The expression level of p-CREB was increased immediately after CWSS and then decreased to a normal level after $15 \mathrm{~min}$ of CWSS (Fig. 2C). Also, CWSS attenuated p-ERK, p-JNK, or pCREB levels in the DRG (Fig. 2D-F). As shown in Fig. 2D and F, both p-ERK and p-CREB expression levels were reduced 0 and $15 \mathrm{~min}$ after CWSS, and then after $30 \mathrm{~min}$, they were reversed to the normal level. The expression level of p-JNK was also downregulated after CWSS and maintained lower than the normal level 30 min after CWSS (Fig. 2E).

\section{Effect of CWSS on the expression of p-AMPK $\alpha 1$, p-AMPK $\alpha 2, p-m T O R$ proteins in the spinal cord and DRG}

Mice were forced to CWSS, and then we tried to assess the phosphorylation level of AMPK or mTOR within the spinal cord and DRG. As shown in Fig. 3A and B, CWSS significantly lowered the expressions of p-AMPK $\alpha 1$ and p-AMPK $\alpha 2$ in the spinal cord at $0-30 \mathrm{~min}$ after CWSS. On the contrary, the level of $\mathrm{p}$ - 
A

Tail flick test

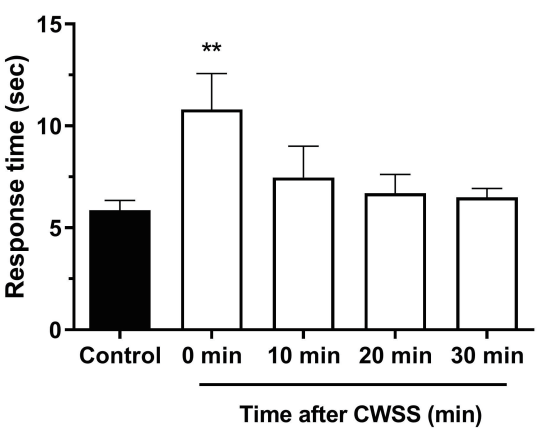

C

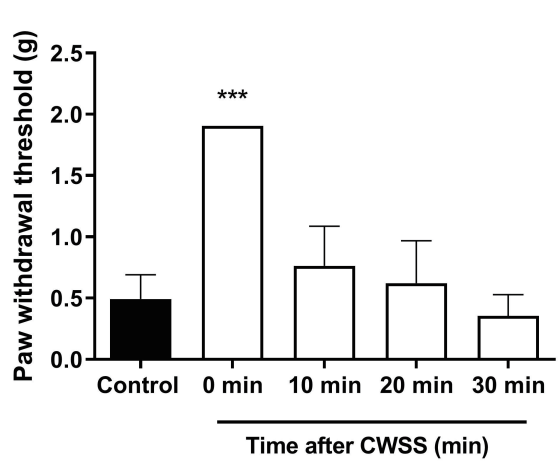

E

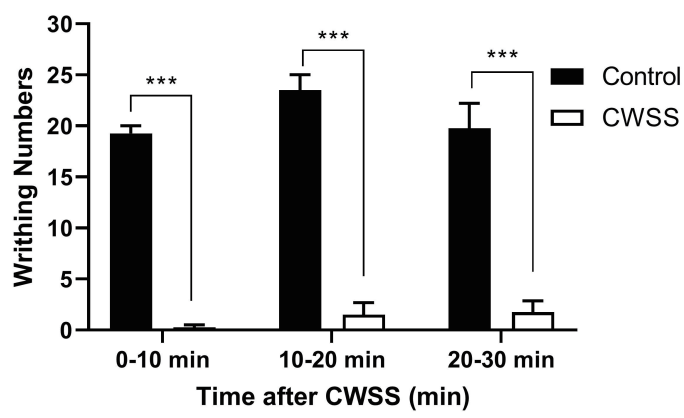

B

Hot plate test

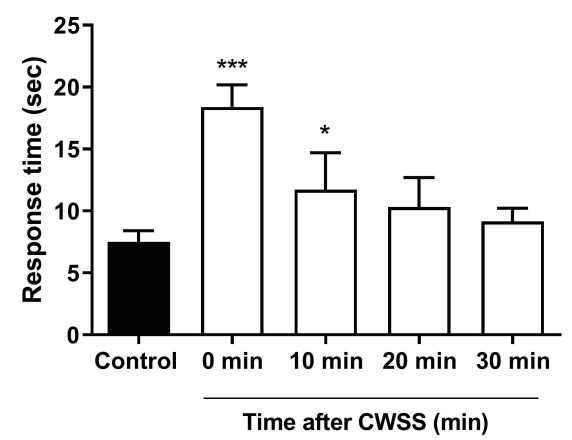

D

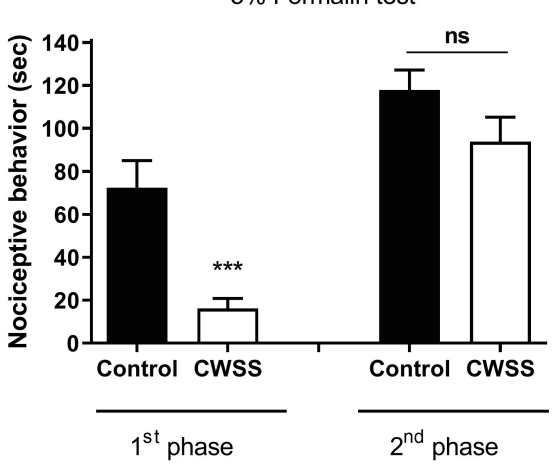

Fig. 1. Effect of acute cold water swimming stress on pain regulation in various pain models. (A) Tail-flick test: The response time of tail-flick to radiant heat was measured. (B) Hot plate test: The latency time spent by mice on the hot plate was examined. (C) Von-Frey test: The withdrawal threshold for the right hind paw was determined. (D) Formalininduced pain model: The pain behaviors such as vigorous licking and shaking paws were counted during the first ( $0-5$ $\mathrm{min}$ ) and the second (20-40 min) phases using a stopwatch. (E) Writhing test: The number of writhing responses was counted for 30 min after acetic acid injection. Values are mean \pm SEM. The mice number of animals used in each group was 5. CWSS, cold-water $\left(4^{\circ} \mathrm{C}\right)$ swimming stress; ns, non-significant. ${ }^{*} p<0.05,{ }^{* *} p$ $<0.01,{ }^{* * *} p<0.001$.
mTOR (Fig. 3C) was elevated in the spinal cord 15 and 30 min after CWSS compared with the normal ones. As shown in Fig. 3D$\mathrm{F}$, the decreased $\mathrm{p}$-AMPK $\alpha 1$ and AMPK $\alpha 2$ level, or increased p-mTOR expression level in DRG were remarkably induced by CWSS. The phosphorylation level of AMPK $\alpha 1$ was significantly decreased 15 and 30 min after CWSS as shown in Fig. 2D. CWSS also reduced the phosphorylation level of AMPK $\alpha 2$ at $0 \mathrm{~min}$ and decreased $\mathrm{p}$-AMPK $\alpha 2$ level was maintained up to $30 \mathrm{~min}$ (Fig. 3E). The expression of p-mTOR level was up-regulated after CWSS which was remained at higher level than the normal level even 30 min after CWSS (Fig. 3F).

\section{Effect of CWSS on the expression of $p$-Tyk2 and p-STAT3 proteins in the spinal cord and DRG}

We next examined the changes of p-Tyk 2 and p-STAT3 proteins after CWSS in the spinal cord and DRG. The p-Tyk2 level in the spinal cord and DRG was immediately decreased at $0 \mathrm{~min}$ and remained at the lower level up to $30 \mathrm{~min}$ after CWSS (Fig. 4A and C). As shown in Fig. 4B, the p-STAT3 level was decreased immediately, remained after $15 \mathrm{~min}$, and then returned to normal level after 30 min of CWSS. As shown in Fig. 4D, the p-STAT3 level was also reduced immediately after CWSS. However, after $15 \mathrm{~min}$, the decreased p-STAT3 level began to elevate gradually, which was still lower than that observed in the normal group. 
A

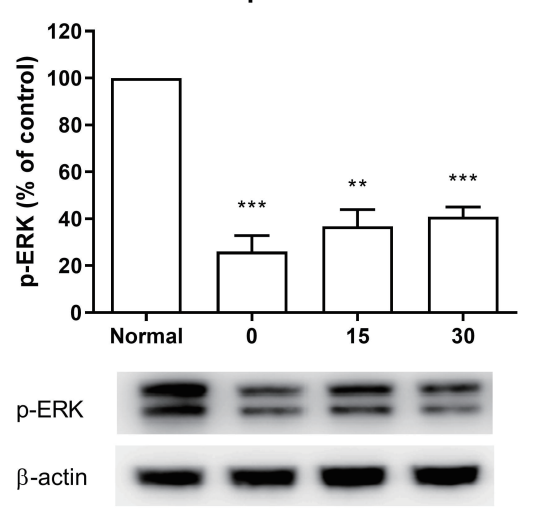

B

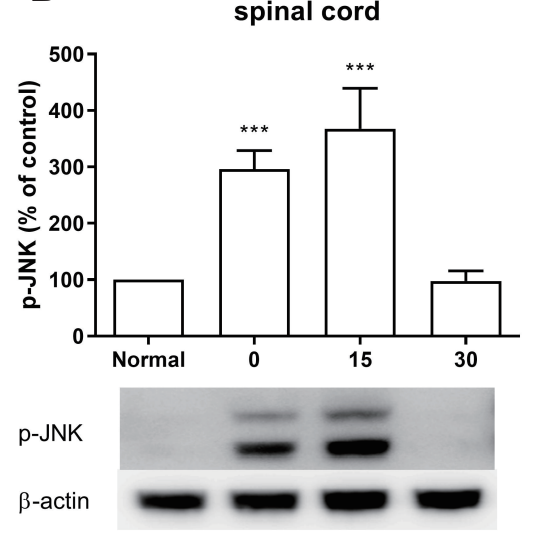

C
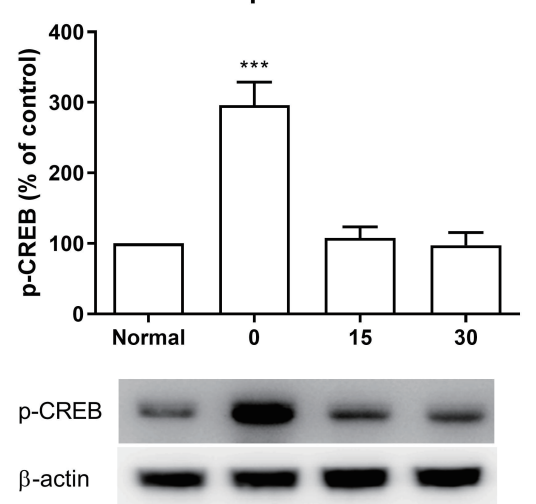

D

DRG
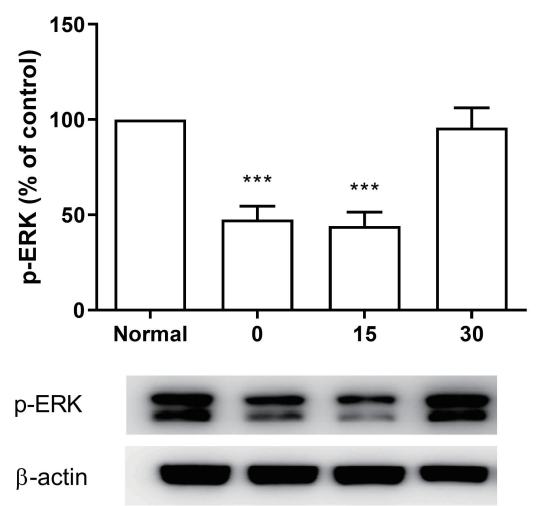

E

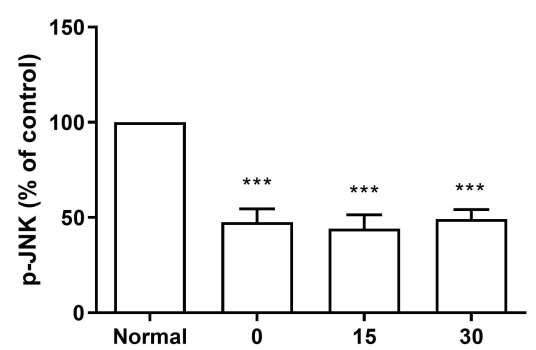

p-JNK

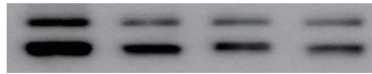

$\beta$-actin

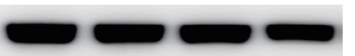

F

DRG

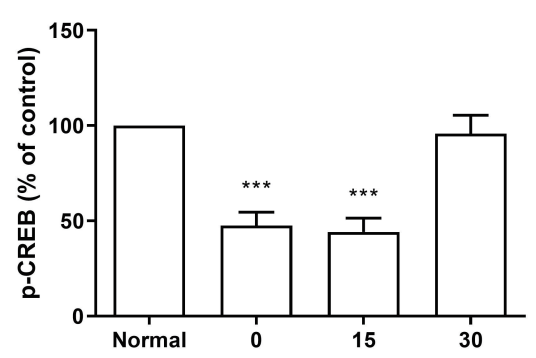

p-CREB

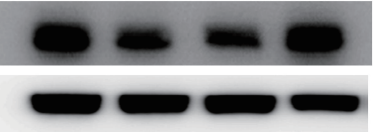

Fig. 2. Effect of acute cold water swimming stress on ERK, JNK, and CREB proteins expression in the spinal cord and DRG. (A) ERK, (B) JNK, (C) CREB proteins phosphorylation in the spinal cord. (D) ERK, (E) JNK, (F) CREB proteins phosphorylation in the DRG. The protein expression was analyzed by Western blot. $\beta$-Actin (1:1,000 dilution) was used as an internal loading control. Signals were quantified with the use of laser scanning densitometry and expressed as a percentage of the control. Values are mean \pm SEM. The number of animals in each group was 6 . ERK, extracellular signalregulated kinase; JNK, c-Jun $\mathrm{N}$-terminal kinase; CREB, CAMP response element binding; DRG, dorsal root ganglia. ${ }^{* *} p<$ 0.01 , $^{* * *} p<0.001$.

\section{DISCUSSION}

In the present study, we examined the effects of CWSS on nociceptive behaviors in various pain models. We found that acute CWSS exerts antinociceptive effects in tail-flick, hot-plate, vonFrey, writhing, and formalin tests. Our results indicate that the CWSS elicit antinociception by inhibiting thermal, chemical, or mechanical noxious stimulus. These results are similar to the findings reported previously. For example, O'Connor and Chipkin [29] have previously reported that acute CWSS $\left(2^{\circ} \mathrm{C}, 3 \mathrm{~min}\right)$ produces a significant increase in the tail-flick latency in mice. Also, Romano and Shih [3] found that acute CWSS $\left(2^{\circ} \mathrm{C}, 3.5 \mathrm{~min}\right)$ produces antinociception in the hot-plate test. As with a series of studies that have reported acute CWSS to induce antinociception being observed in both of two phases of formalin response, contrarily, in this study, we find that CWSS attenuated only the first phase of formalin response, but not the second phase. It has been known that the intraplantar injection produces a biphasic reaction [30]. The nociceptive behavior observed during the first phase is mostly due to the direct stimulation of nociceptors, 
A

spinal cord

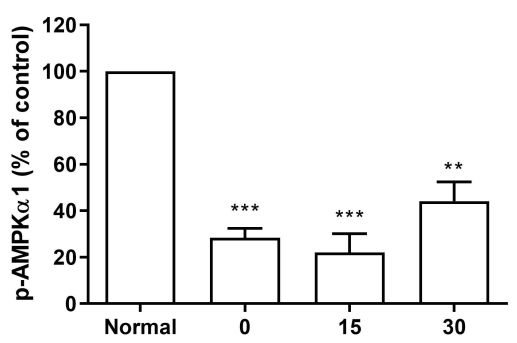

p-AMPK $\alpha 1$

$\beta$-actin

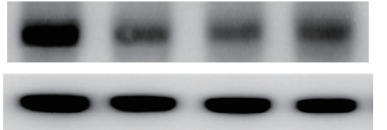

B

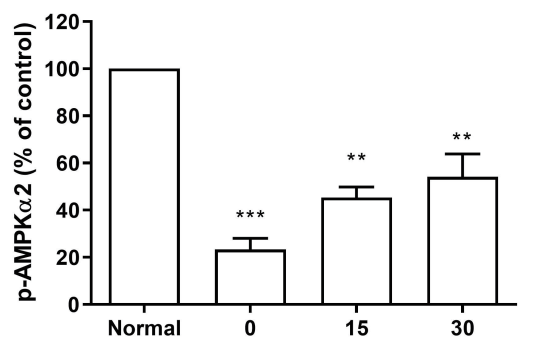

p-AMPK $\alpha 2$

$\beta$-actin

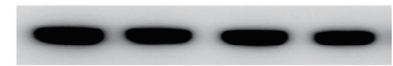

C

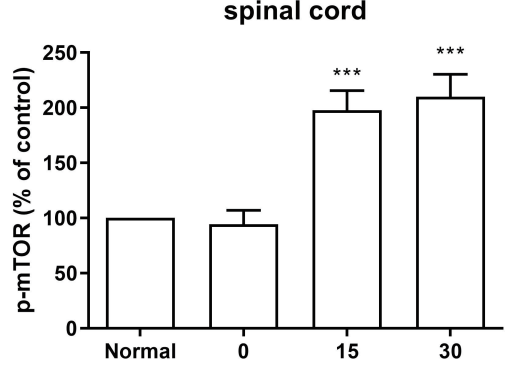

p-mTOR

$\beta$-actin
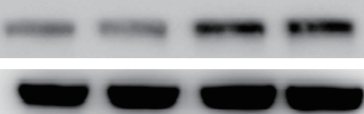

D

DRG

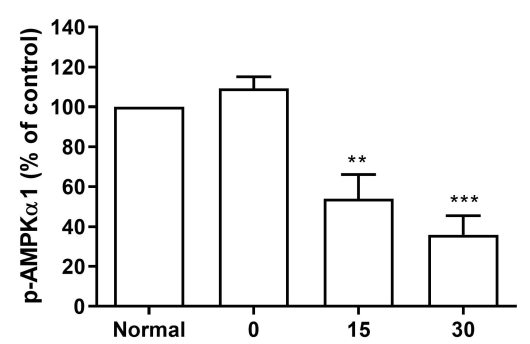

p-AMPK $\alpha 1$

$\beta$-actin

E

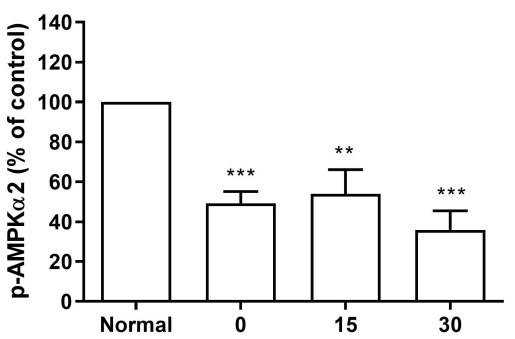

p-AMPK $\alpha 2$

$\beta$-actin

$\mathbf{F}$

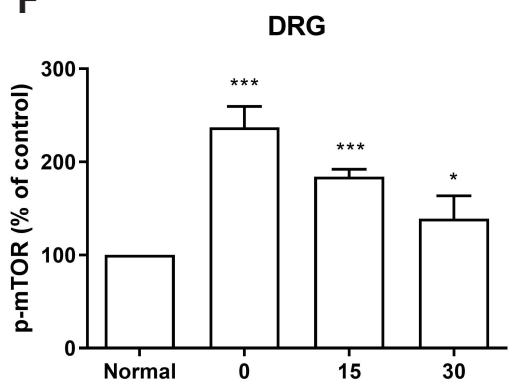

p-mTOR

$\beta$-actin
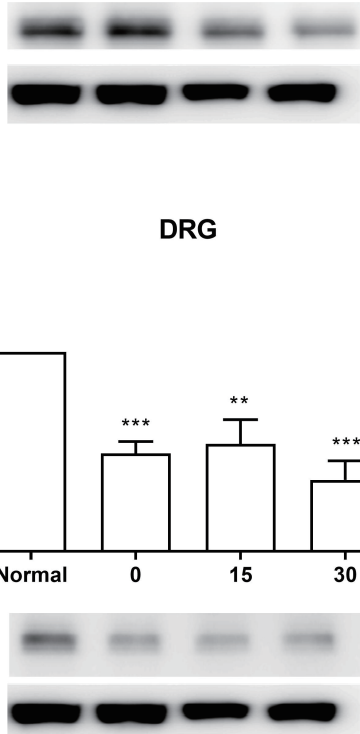

DRG
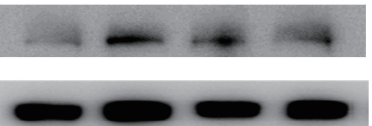

Fig. 3. Effect of acute cold water swimming stress on AMPK and mTOR proteins expression in the spinal cord and DRG. (A) AMPKa1, (B) AMPKa2, (C) mTOR proteins phosphorylation in the spinal cord. (D) AMPKa1, (E) AMPKa2, (F) mTOR proteins phosphorylation in DRG. The protein expression was analyzed by Western blot. $\beta$-Actin (1:1,000 dilution) was used as an internal loading control. Signals were quantified with the use of laser scanning densitometry and expressed as a percentage of the control. Values are mean \pm SEM. The number of animals in each group was 6 . AMPK, adenosine monophosphate protein kinase; mTOR, mammalian target of rapamycin; DRG, dorsal root ganglia. ${ }^{*} p<0.05,{ }^{* *} p<$ $0.01,{ }^{* * *} p<0.001$. whereas the nociceptive behaviors observed during the second phase involves both inflammatory mechanisms and central sensitization within the dorsal horn [31], suggesting that nociceptive behaviors observed during the first and second phases are differentially regulated. On the other hand, CWSS $\left(2^{\circ} \mathrm{C}, 3.5 \mathrm{~min}\right)$ delayed the nociceptive response in the formalin test in rats [32]. Taken together, we speculated that these differential effects of CWSS in the formalin test might be resulted from the differential origins of animals or the dose of the formalin injected.

Interestingly, in the present study, we found that the writhing test differs from other nociceptive models. The antinociceptive effect induced by CWSS could last a longer time in the writhing test than other nociceptive models. Although the exact reason for this effect is currently unknown, acetic acid-induced pain modality might be different from other pain models.

Several lines of evidence have previously demonstrated that ERK protein is closely associated with pain transmission. For example, p-ERK expressions in the spinal cord or dorsal root ganglia are up-regulated in various chronic pain models, such as neuropathic pain and neuropathy [33]. Furthermore, the expression ERK protein in the spinal cord or brain regions are up-regulated in an acute inflammatory pain model such as the formalin pain 
A

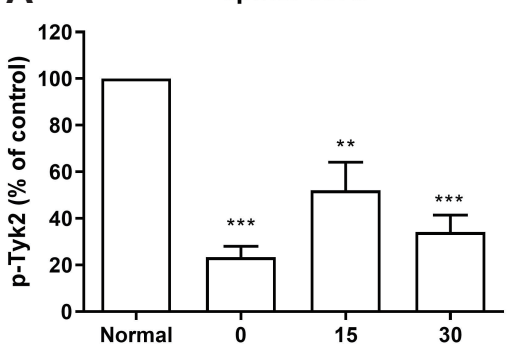

p-Tyk2

$\beta$-actin

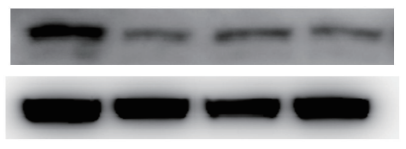

C
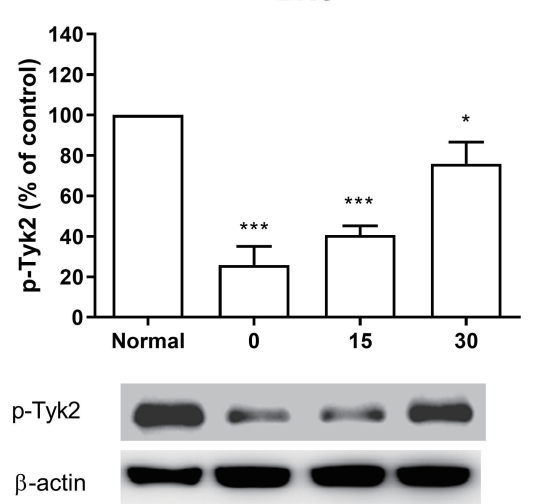

B
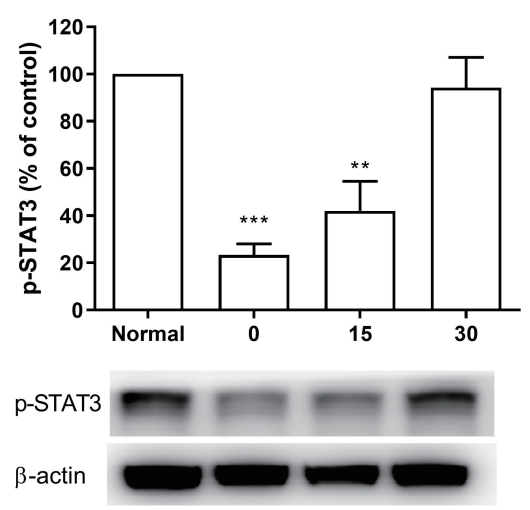

D

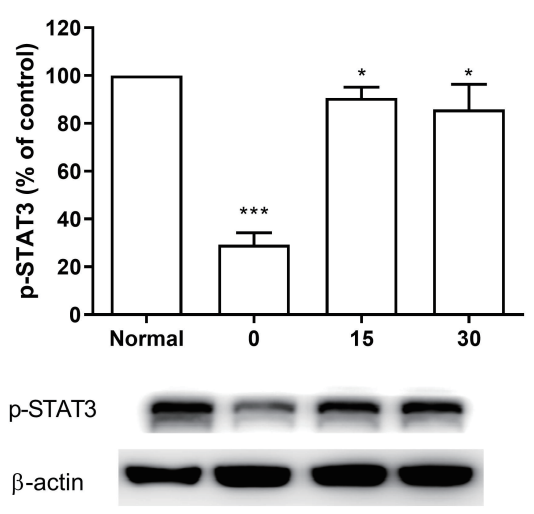

Fig. 4. Effect of acute cold water swimming stress on Tyk2 and STAT3 proteins expression in the spinal cord and DRG. (A) Tyk2, (B) STAT3 proteins phosphorylation in the spinal cord. (C) Tyk2, (D) STAT3 proteins phosphorylation in the DRG. The protein expression was analyzed by Western blot. $\beta$-Actin (1:1,000 dilution) was used as an internal loading control. Signals were quantified with the use of laser scanning densitometry and expressed as a percentage of the control. Values are mean \pm SEM. The number of animals in each group was 6. Tyk2, Tyrosine Kinase 2; STAT3, Signal transducer and activator of transcription 3; DRG, dorsal root ganglia. ${ }^{*} p<0.05$, ${ }^{* *} p<0.01,{ }^{* * *} p<0.001$. model $[34,35]$. In the present study, we found that, after CWSS, the p-ERK expression was suppressed in the spinal cord and DRG, suggesting that the down-regulation of p-ERK expression is closely associated with the CWSS-induced antinociception.

Additionally, JNK and CREB proteins are closely associated with pain transmission. In the present study, we found that CWSS resulted in a significant decrease in the level of $\mathrm{p}$-CREB and p-JNK expression in DRG. In addition, the finding by other groups supports, in part, our results. For example, both p-CREB and $\mathrm{p}$-JNK expression in the DRG are up-regulated in various pain models, such as cancer and inflammatory pain models $[36,37]$. However, in the present study, we found that the p-CREB and p-JNK levels in the spinal cord are increased after CWSS. The spinal cord is a location that the ascending track of the pain transmission and the descending track of pain inhibitory system meet, whereas the DRG is mostly involved in the pain transmission from the peripheral system to the spinal cord $[38,39]$. Thus, we infer that the different effect on the protein expression level of p-CREB and p-JNK in the spinal cord and DRG may be due to their location and function. Previously, we reported that CWSS produces antinociception, which might be induced by the deltaand mu-opioid receptors in the brainstem, midbrain, and spinal cord areas [40]. Besides, cholecystokinin (CCK) receptors, located at supraspinal and spinal regions, contributed to the antagonism against supraspinally administered opioid-induced antinociception [41]. We further found that, at the supraspinal level, CCK(A), but not $\mathrm{CCK}(\mathrm{B})$ receptor, was involved in antagonizing the CWSS-induced antinociception [41]. In addition, we concluded that spinal, but not supraspinal, pertussis toxin-sensitive Gproteins and CAMP phosphodiesterase may be involved in the antinociception produced by CWSS [42]. Taken together, although the exact reasons for the differential regulation of $\mathrm{p}$-CREB and $\mathrm{p}$ JNK in the spinal cord and DRG by CWSS are currently not clear, these lines of evidence suggest that multiple endogenous ascending and the descending pain inhibitory systems during the CWSS might be involved.

Recent studies provide evidence for AMPK and mTOR's different role in the acute and neuropathic pain models [43-46]. Numerous studies reported that the activation of AMPK might contribute to their antinociceptive effect $[47,48]$. Moreover, the inhibition of mTOR was identified as a potential therapy for chronic inflammatory pain [49] and neuropathic pain [50,51]. We found, in the present study, that CWSS decreases p-AMPK $\alpha 1$ and p-AMPK $\alpha 2$ levels but increased p-mTOR level in the spinal cord and DRG. AMPK is a known regulator of whole-body energy homeostasis. Our finding supports the concept that the activation of AMPK, in general, inhibits the mTOR phosphorylation [52,53]. However, $\mathrm{Lu}$ and $\mathrm{Xu}$ [54] previously reported that four weeks of 
cold exposure $\left(4^{\circ} \mathrm{C}\right)$ significantly augmented the phosphorylation expression of AMPK [54]. Our previous study indicates that acute CWSS and chronic CWSS can cause different effects on mice [40], as well as Shi et al. [55]. Thus, we speculate that the various AMPK expression level changes after cold stress may result from the different types or the time of stress.

STAT-JAK pathway is also known to be involved in pain transmission under inflammatory and neuropathy conditions [5659]. Over-expression of STAT3 was observed in neuropathic pain model and the suppression of the p-STAT3 level could alleviate neuropathic pain in the spinal cord and DRG [15,60-63]. Moreover, the Tyk2 protein belongs to JAK families and is considered as an upstream kinase of STATs [64]. We found, in the present study, that CWSS caused decreases of p-Tyk2 and p-STAT levels in the spinal cord and DRG, supporting further the STAT3 and Tyk2 proteins appeared to be associated with the antinociception induced by CWSS.

In conclusion, cold water swimming stress-induced antinociception in thermal, chemical, or mechanical noxious stimulus models. Several signaling molecules, such as ERK, JNK, CREB, AMPK $\alpha 1$, p-AMPK $\alpha 2$, mTOR, Tyk2, and STAT3 in the spinal cord and DRG, were appeared to be involved in the antinociception induced by cold water swimming stress.

\section{ACKNOWLEDGEMENTS}

This research was supported by Basic Science Research Program through the National Research Foundation of Korea (NRF) funded by the Ministry of Science, ICT \& Future Planning (2017M3C7A1020062).

\section{CONFLICTS OF INTEREST}

The authors declare no conflicts of interest.

\section{REFERENCES}

1. Fazli-Tabaei S, Yahyavi SH, Nouri M, Zartab H, Javid G, Loghavi S, Zarrindast MR. Dopamine receptor mechanism(s) and antinociception and tolerance induced by swim stress in formalin test. Behav Pharmacol. 2006;17:341-347.

2. Oluyomi AO, Hart SL. Alpha-adrenoceptor involvement in swim stress-induced antinociception in the mouse. J Pharm Pharmacol. 1990;42:778-784.

3. Romano JA, Shih TM. Cholinergic mechanisms of analgesia produced by physostigmine, morphine and cold water swimming. Neuropharmacology. 1983;22:827-833.

4. Vaswani KK, Richard CW 3rd, Tejwani GA. Cold swim stressinduced changes in the levels of opioid peptides in the rat CNS and peripheral tissues. Pharmacol Biochem Behav. 1988;29:163-168.
5. von Hehn CA, Baron R, Woolf CJ. Deconstructing the neuropathic pain phenotype to reveal neural mechanisms. Neuron. 2012;73:638652.

6. Costigan M, Scholz J, Woolf CJ. Neuropathic pain: a maladaptive response of the nervous system to damage. Annu Rev Neurosci. 2009;32:1-32.

7. Woolf CJ, Ma Q. Nociceptors--noxious stimulus detectors. Neuron. 2007;55:353-364.

8. Dubin AE, Patapoutian A. Nociceptors: the sensors of the pain pathway. J Clin Invest. 2010;120:3760-3772.

9. Butler RK, Finn DP. Stress-induced analgesia. Prog Neurobiol. 2009; 88:184-202.

10. Li ZY, Huang Y, Yang YT, Zhang D, Zhao Y, Hong J, Liu J, Wu LJ, Zhang CH, Wu HG, Zhang J, Ma XP. Moxibustion eases chronic inflammatory visceral pain through regulating MEK, ERK and CREB in rats. World J Gastroenterol. 2017;23:6220-6230.

11. Zhang T, Zhang N, Zhang R, Zhao W, Chen Y, Wang Z, Xu B, Zhang M, Shi X, Zhang Q, Guo Y, Xiao J, Chen D, Fang Q. Preemptive intrathecal administration of endomorphins relieves inflammatory pain in male mice via inhibition of p38 MAPK signaling and regulation of inflammatory cytokines. J Neuroinflammation. 2018; 15:320.

12. Zhou J, Lin W, Chen H, Fan Y, Yang C. TRESK contributes to pain threshold changes by mediating apoptosis via MAPK pathway in the spinal cord. Neuroscience. 2016;339:622-633.

13. Ma W, Quirion R. The ERK/MAPK pathway, as a target for the treatment of neuropathic pain. Expert Opin Ther Targets. 2005;9: 699-713.

14. Smith MT, Woodruff TM, Wyse BD, Muralidharan A, Walther T. A small molecule angiotensin II type 2 receptor $\left(\mathrm{AT}_{2} \mathrm{R}\right)$ antagonist produces analgesia in a rat model of neuropathic pain by inhibition of p38 mitogen-activated protein kinase (MAPK) and p44/p42 MAPK activation in the dorsal root ganglia. Pain Med. 2013;14:15571568.

15. Ge A, Wang S, Miao B, Yan M. Effects of metformin on the expression of AMPK and STAT3 in the spinal dorsal horn of rats with neuropathic pain. Mol Med Rep. 2018;17:5229-5237.

16. Liu Y, Li J, Li H, Shang Y, Guo Y, Li Z, Liu Z. AMP-activated protein kinase activation in dorsal root ganglion suppresses mTOR/p70S6K signaling and alleviates painful radiculopathies in lumbar disc herniation rat model. Spine (Phila Pa 1976). 2019;44:E865-E872.

17. Zhang Y, Tao GJ, Hu L, Qu J, Han Y, Zhang G, Qian Y, Jiang CY, Liu WT. Lidocaine alleviates morphine tolerance via AMPK-SOCS3dependent neuroinflammation suppression in the spinal cord. $J$ Neuroinflammation. 2017;14:211.

18. Izumi Y, Sasaki M, Hashimoto S, Sawa T, Amaya F. mTOR signaling controls VGLUT2 expression to maintain pain hypersensitivity after tissue injury. Neuroscience. 2015;308:169-179.

19. Xing X, Wu K, Dong Y, Zhou Y, Zhang J, Jiang F, Hu WP, Li JD. Hyperactive Akt-mTOR pathway as a therapeutic target for pain hypersensitivity in Cntnap2-deficient mice. Neuropharmacology. 2020;165:107816.

20. Salaffi F, Giacobazzi G, Di Carlo M. Chronic pain in inflammatory arthritis: mechanisms, metrology, and emerging targets-a focus on the JAK-STAT pathway. Pain Res Manag. 2018;2018:8564215.

21. Ding HH, Zhang SB, Lv YY, Ma C, Liu M, Zhang KB, Ruan XC, Wei JY, Xin WJ, Wu SL. TNF- $\alpha /$ STAT3 pathway epigenetically upregu- 
lates Nav1.6 expression in DRG and contributes to neuropathic pain induced by L5-VRT. J Neuroinflammation. 2019;16:29.

22. Xu M, Ni H, Xu L, Shen H, Deng H, Wang Y, Yao M. B14 ameliorates bone cancer pain through downregulating spinal interleukin$1 \beta$ via suppressing neuron JAK2/STAT3 pathway. Mol Pain. 2019; 15:1744806919886498.

23. Horan P, Taylor J, Yamamura HI, Porreca F. Extremely long-lasting antagonistic actions of nor-binaltorphimine (nor-BNI) in the mouse tail-flick test. J Pharmacol Exp Ther. 1992;260:1237-1243.

24. Noble F, Roques BP. Assessment of endogenous enkephalins efficacy in the hot plate test in mice: comparative study with morphine. Neurosci Lett. 1995;185:75-78.

25. Bonin RP, Bories C, De Koninck Y. A simplified up-down method (SUDO) for measuring mechanical nociception in rodents using von Frey filaments. Mol Pain. 2014;10:26.

26. Hunskaar S, Fasmer OB, Hole K. Formalin test in mice, a useful technique for evaluating mild analgesics. J Neurosci Methods. 1985; 14:69-76.

27. Hunskaar S, Hole K. The formalin test in mice: dissociation between inflammatory and non-inflammatory pain. Pain. 1987;30:103-114.

28. Feng JH, Lee HJ, Suh HW. The molecular signatures of acute-immobilization-induced antinociception and chronic-immobilizationinduced antinociceptive tolerance. Exp Neurobiol. 2019;28:670-678.

29. O'Connor P, Chipkin RE. Comparisons between warm and cold water swim stress in mice. Life Sci. 1984;35:631-639.

30. Barrot M. Tests and models of nociception and pain in rodents. Neuroscience. 2012;211:39-50.

31. Tjølsen A, Berge OG, Hunskaar S, Rosland JH, Hole K. The formalin test: an evaluation of the method. Pain. 1992;51:5-17.

32. Fuchs PN, Kerr B, Melzack R. Delayed nociceptive response following cold-water swim in the formalin test: possible mechanisms of action. Exp Neurol. 1996;139:291-298.

33. Song XS, Cao JL, Xu YB, He JH, Zhang LC, Zeng YM. Activation of ERK/CREB pathway in spinal cord contributes to chronic constrictive injury-induced neuropathic pain in rats. Acta Pharmacol Sin. 2005;26:789-798.

34. Korneyev AY. Stress-induced tau phosphorylation in mouse strains with different brain Erk $1+2$ immunoreactivity. Neurochem Res. 1998;23:1539-1543.

35. Chaudhary SC, Siddiqui MS, Athar M, Alam MS. D-Limonene modulates inflammation, oxidative stress and Ras-ERK pathway to inhibit murine skin tumorigenesis. Hum Exp Toxicol. 2012;31:798811.

36. Xie AX, Pan XQ, Meacham RB, Malykhina AP. The expression of transcription factors Mecp2 and CREB is modulated in inflammatory pelvic pain. Front Syst Neurosci. 2019;12:69.

37. Chen SP, Sun J, Zhou YQ, Cao F, Braun C, Luo F, Ye DW, Tian YK. Sinomenine attenuates cancer-induced bone pain via suppressing microglial JAK2/STAT3 and neuronal CAMKII/CREB cascades in rat models. Mol Pain. 2018;14:1744806918793232.

38. Duan B, Cheng L, Ma Q. Spinal circuits transmitting mechanical pain and itch. Neurosci Bull. 2018;34:186-193.

39. Zhuo M. Descending facilitation: from basic science to the treatment of chronic pain. Mol Pain. 2017;13:1744806917699212.

40. Kim KW, Choi SS, Woo RS, Suh HW. Development of antinociceptive tolerance and changes of opioid receptor ligand binding in central nervous system of the mouse forced to single and repeated swimming in the cold water. Brain Res Bull. 2003;61:93-97.

41. Suh HW, Kim YH, Choi YS, Song DK. Involvement of different subtypes of cholecystokinin receptors in opioid antinociception in the mouse. Peptides. 1995;16:1229-1234.

42. Suh HW, Song DK, Kwon SH, Kim KW, Min BH, Kim YH. Effects of spinally and supraspinally injected 3-isobutyl-1-methylxanthine, cholera toxin, and pertussis toxin on cold water swimming stressinduced antinociception in the mouse. Gen Pharmacol. 1997;28:607610.

43. Um SW, Kim MJ, Leem JW, Bai SJ, Lee BH. Pain-relieving effects of mTOR inhibitor in the anterior cingulate cortex of neuropathic rats. Mol Neurobiol. 2019;56:2482-2494.

44. Duan Z, Li J, Pang X, Wang H, Su Z. Blocking mammalian target of rapamycin (mTOR) alleviates neuropathic pain induced by chemotherapeutic bortezomib. Cell Physiol Biochem. 2018;48:54-62.

45. Yin X, Jing Y, Chen Q, Abbas AB, Hu J, Xu H. The intraperitoneal administration of MOTS-c produces antinociceptive and antiinflammatory effects through the activation of AMPK pathway in the mouse formalin test. Eur J Pharmacol. 2020;870:172909.

46. Augusto PSA, Braga AV, Rodrigues FF, Morais MI, Dutra MMGB, Batista CRA, Melo ISF, Costa SOAM, Goulart FA, Coelho MM, Machado RR. Metformin antinociceptive effect in models of nociceptive and neuropathic pain is partially mediated by activation of opioidergic mechanisms. Eur J Pharmacol. 2019;858:172497.

47. Burton MD, Tillu DV, Mazhar K, Mejia GL, Asiedu MN, Inyang K, Hughes T, Lian B, Dussor G, Price TJ. Pharmacological activation of AMPK inhibits incision-evoked mechanical hypersensitivity and the development of hyperalgesic priming in mice. Neuroscience. 2017;359:119-129.

48. Russe OQ, Möser CV, Kynast KL, King TS, Stephan H, Geisslinger G, Niederberger E. Activation of the AMP-activated protein kinase reduces inflammatory nociception. J Pain. 2013;14:1330-1340.

49. Liang L, Tao B, Fan L, Yaster M, Zhang Y, Tao YX. mTOR and its downstream pathway are activated in the dorsal root ganglion and spinal cord after peripheral inflammation, but not after nerve injury. Brain Res. 2013;1513:17-25.

50. Kwon M, Han J, Kim UJ, Cha M, Um SW, Bai SJ, Hong SK, Lee BH. Inhibition of mammalian target of rapamycin (mTOR) signaling in the insular cortex alleviates neuropathic pain after peripheral nerve injury. Front Mol Neurosci. 2017;10:79.

51. Lisi L, Aceto P, Navarra P, Dello Russo C. mTOR kinase: a possible pharmacological target in the management of chronic pain. Biomed Res Int. 2015;2015:394257.

52. Xu J, Ji J, Yan XH. Cross-talk between AMPK and mTOR in regulating energy balance. Crit Rev Food Sci Nutr. 2012;52:373-381.

53. Inoki K, Kim J, Guan KL. AMPK and mTOR in cellular energy homeostasis and drug targets. Annu Rev Pharmacol Toxicol. 2012;52:381-400.

54. Lu S, Xu D. Cold stress accentuates pressure overload-induced cardiac hypertrophy and contractile dysfunction: role of TRPV1/ AMPK-mediated autophagy. Biochem Biophys Res Commun. 2013; 442:8-15.

55. Shi SS, Shao SH, Yuan BP, Pan F, Li ZL. Acute stress and chronic stress change brain-derived neurotrophic factor (BDNF) and tyrosine kinase-coupled receptor (TrkB) expression in both young and aged rat hippocampus. Yonsei Med J. 2010;51:661-671.

56. Busch-Dienstfertig M, González-Rodríguez S. IL-4, JAK-STAT sig- 
naling, and pain. JAKSTAT. 2013;2:e27638.

57. Tsuda M, Kohro Y, Yano T, Tsujikawa T, Kitano J, Tozaki-Saitoh H, Koyanagi S, Ohdo S, Ji RR, Salter MW, Inoue K. JAK-STAT3 pathway regulates spinal astrocyte proliferation and neuropathic pain maintenance in rats. Brain. 2011;134(Pt 4):1127-1139.

58. Wang S, Li A, Guo S. Ligustrazine attenuates neuropathic pain by inhibition of JAK/STAT3 pathway in a rat model of chronic constriction injury. Pharmazie. 2016;71:408-412.

59. Pang H, Ren Y, Li H, Chen C, Zheng X. LncRNAs linc00311 and AK141205 are identified as new regulators in STAT3-mediated neuropathic pain in bCCI rats. Eur J Pharmacol. 2020;868:172880.

60. Zhang XS, Li X, Luo HJ, Huang ZX, Liu CC, Wan Q, Xu SW, Wu SL, Ke SJ, Ma C. Activation of the RAGE/STAT3 pathway in the dorsal root ganglion contributes to the persistent pain hypersensitivity induced by lumbar disc herniation. Pain Physician. 2017;20:419-427.
61. Li YY, Li H, Liu ZL, Li Q, Qiu HW, Zeng LJ, Yang W, Zhang XZ, Li ZY. Activation of STAT3-mediated CXCL12 up-regulation in the dorsal root ganglion contributes to oxaliplatin-induced chronic pain. Mol Pain. 2017;13:1744806917747425.

62. Lee SY, Lee SH, Na HS, Kwon JY, Kim GY, Jung K, Cho KH, Kim SA, Go EJ, Park MJ, Baek JA, Choi SY, Jhun J, Park SH, Kim SJ, Cho ML. The therapeutic effect of STAT3 signaling-suppressed MSC on pain and articular cartilage damage in a rat model of monosodium Iodoacetate-induced osteoarthritis. Front Immunol. 2018;9:2881.

63. Wang B, Liu S, Fan B, Xu X, Chen Y, Lu R, Xu Z, Liu X. PKM2 is involved in neuropathic pain by regulating ERK and STAT3 activation in rat spinal cord. J Headache Pain. 2018;19:7.

64. Wöss K, Simonović N, Strobl B, Macho-Maschler S, Müller M. TYK2: an upstream kinase of STATs in cancer. Cancers (Basel). 2019;11:1728. 